Article

\title{
'A Shared Reality between a Journalist and the Audience': How Live Journalism Reimagines News Stories
}

\author{
Juho Ruotsalainen ${ }^{1, *}$ and Mikko Villi ${ }^{2}$ \\ ${ }^{1}$ Finland Futures Research Centre, University of Turku, FI-00130 Helsinki, Finland; E-Mail: juho.ruotsalainen@utu.fi \\ 2 Department of Language and Communication Studies, University of Jyväskylä, Fl-40014 Jyväskylä, Finland; \\ E-Mail: mikko.villi@jyu.fi \\ * Corresponding author
}

Submitted: 31 October 2020 | Accepted: 22 December 2020 | Published: 6 May 2021

\begin{abstract}
Live journalism is a new journalistic genre in which journalists present news stories to a live audience. This article investigates the journalistic manuscripts of live journalism performances. With the focus on texts, the article reaches beyond the live performance to explore the wider implications and potentials pioneered by live journalists. The data were gathered from Musta laatikko ('Black Box') manuscripts, a live journalism production by the Finnish newspaper Helsingin Sanomat. The manuscripts were analysed as eudaimonic journalism through four conceptual dimensions: self-transcendence, autonomy, competence, and relatedness. The results show how eudaimonic journalism can contemplate history, the future, and the meaning of finite human life. Moreover, by describing self-determinant individuals and communal social relationships, eudaimonic news stories can foster a sense of meaning and agency in audience members. By employing eudaimonia, journalists at large can reflect on the meaning and purpose of contemporary life and offer a more comprehensive understanding of the world. Such understanding includes not only facts and analysis, but also values, affects, and collective meanings mediated through the subjectivity of a journalist.
\end{abstract}

\section{Keywords}

eudaimonia; live journalism; reciprocal journalism; self-determination theory; self-transcendence; slow journalism

\section{Issue}

This article is part of the issue "The Good, the Bad, and the Ugly: Inspirational Media between Meaning, Narration, and Manipulation" edited by Lena Frischlich (University of Muenster, Germany), Diana Rieger (LMU Munich, Germany) and Lindsay Hahn (University at Buffalo-State University of New York, USA).

(C) 2021 by the authors; licensee Cogitatio (Lisbon, Portugal). This article is licensed under a Creative Commons Attribution 4.0 International License (CC BY).

\section{Introduction}

Several experiments of live journalism have emerged during recent years in response to the many challenges facing contemporary journalism. In live journalism, journalists present journalistic contents to a live audience in a theatre or similar venue. The embodied performance of journalistic stories is thought to enhance the audience's interest, engagement, and trust toward journalism (Adams, 2020). Live journalism can thus aid in the intense contest for audiences' attention and make them more willing to consume and pay for journalism (Adams, 2020; Tenenboim \& Stroud, 2020).
Live journalism is part of an 'audience turn' in journalism, which emphasises the importance of the needs and attention of audiences in shaping how journalism develops (Kormelink \& Costera Meijer, 2015). Journalists often respond to the assumed needs of the audiences by offering them affectively engaging content or, increasingly, individual and communal experiences (Vodanovic, 2020). The audience turn has made some observers fear that journalism is losing its autonomy and falling prey to commercialisation and excessive emotion (Vodanovic, 2020). Many in the industry thus feel a need to reimagine journalistic offerings and norms in an audience-friendly but journalistically sustainable way (Kormelink \& Costera Meijer, 2015). 
Previous research on live journalism has focused on the human presence of a journalist in live performances and the different aspects of audiences' engagement with the journalism and each other. Adams (2020) examines whether live events can be successful in re-establishing journalism's authority and role as a truth-teller through meaningful face-to-face experiences. Tenenboim and Stroud (2020) find that immersive and affectively powerful 'enacted journalism' can increase people's political knowledge, forge reciprocal communal connections, and increase intention to participate in civic and political life. Focusing on the aesthetics of live journalism events, Vodanovic (2020) observes that their informal, conversational, and subjective registers support deep reflection and making sense of news, similarly to 'slow journalism' (Andersen, 2020).

Previous studies have largely eschewed analysis of the contents of the journalistic presentations in live journalism events. Research also lacks reflection on how the new ideas and approaches of live journalism could be applied in journalism more broadly. This article contributes to research, first, by examining journalistic contents in the manuscripts of Musta laatikko ('Black Box' in Finnish), a live journalism production by the Finnish legacy newspaper Helsingin Sanomat (an example of a Musta laatikko presentation, with English subtitles, can be viewed at https://drive.google.com/file/d/ 1QEtXhN6isow8utdnrloF_Bs0EOJ9FaR2/view). The article approaches the Musta laatikko manuscripts as eudaimonic journalism which presents and analyses news events from the perspective of human virtues, meanings, and potentials (see Ryan, Huta, \& Deci, 2013). Like previous studies on eudaimonic media, the article suggests eudaimonic journalism as a 'serious' alternative to conventional media entertainment or 'infotainment.' In eudaimonically entertaining journalism, enjoyment is not based on immediate pleasure but on a sense of meaningfulness and reflections on the purpose of life (Oliver et al., 2018; Pelzer \& Raemy, 2020). Eudaimonic journalism is by no means restricted to live performances; however, live journalists can be seen as pioneers who apply eudaimonia in journalism and explore new journalistic ideas that can also potentially be applied in other journalistic forms. The article thus explores how live journalism and eudaimonic journalism can contribute to existing conceptualisations of contemporary journalism.

These considerations give rise to the following research questions:

RQ1: How is a sense of eudaimonia implied and produced in Musta laatikko manuscripts?

RQ2: How can the journalistic ideas of eudaimonic live journalism be applied in journalism outside the live setting?
Before answering the research questions in Sections 4, 5 , and 6, Sections 2 and 3 review previous research and connect live journalism and eudaimonic journalism with slow journalism and journalistic reciprocity.

\section{Live Journalism}

The recent live journalism initiatives range from discussion and networking events by legacy media organisations such as the Washington Post and 'stand-up journalism' by the Pop-Up Magazine in the United States, to theatre plays based on journalistic reporting like Camden People's Theatre in the UK and the more 'serious' journalism by the Finnish Musta laatikko (Larson, 2015; Lyytinen, 2020; Vodanovic, 2020). Although the cases of live journalism vary, they share some core motivations, ideas, and purposes. First, presenting journalism to a live audience can tap on the affective interest of audience members through an animated, embodied delivery of news (Adams, 2020). Second, live journalism events can establish a stronger and interpersonal connection between journalists and audience members (Lyytinen, 2020). They can enhance audiences' trust towards journalists (Larson, 2015) and foster a sense of community between attendees (Adams, 2020). Third, live events bring in new income to news organisations (Larson, 2015). Fourth, such events can strengthen the brand of both news organisations and individual journalists by highlighting their journalistic mission and transparency (Vodanovic, 2020).

The embodied experience of live journalism can aid immersion in news stories and allow audience members to take "the same journey all together" (Tenenboim \& Stroud, 2020, p. 15). Live journalism can bolster political knowledge and strengthen individuals' sense of connectedness to fellow citizens and the public spheres beyond their private lives (Tenenboim \& Stroud, 2020). However, hopes that live journalism might re-animate public debate may, at least for now, prove overblown as often the communication in live events is one-way, from a journalist to the audience (Adams, 2020; Vodanovic, 2020). Yet despite the conventional hierarchies, live events can help newsrooms become better enmeshed in their communities (Tenenboim \& Stroud, 2020). This is particularly due to the direct, immediate, and intimate connection between live journalists and the audience (Barker, 2003; Vodanovic, 2020). Moreover, although the performances usually are one-directional, live journalism events often include an opportunity for the audience to have an informal discussion with the journalists afterwards (Lyytinen, 2020; Tenenboim \& Stroud, 2020).

The shared, communal experience of live journalism has important epistemological repercussions. According to Adams (2020, p. 10), audiences at live events find "truth" as they experience journalists' honesty and feel trust towards them, perceiving them as "real people." Vodanovic (2020) emphasises how live journalism is to make sense of news rather than break it. Making sense 
involves representing shared beliefs and the "truth of shared experiences" alongside imparting more neutral information (Adams, 2020, p. 2). The social, physical, and subjective aspects of journalists performing their stories to a live audience can draw audience members deeper into the stories and bring them to life in the viewers' subjective experience (Tenenboim \& Stroud, 2020).

Compared to prior forms of journalism, live journalism comes close particularly to slow journalism (Vodanovic, 2020). Rather than a distinct genre, slow journalism is an approach or sensibility toward the production of journalism. Slow journalism detaches from the daily and weekly news grind in favour of rigorous fact-gathering, the composing of compelling stories, and careful editing (Le Masurier, 2015). It encourages audience members to reflect the complexities of contemporary existence and democratic life (Craig, 2016). Instead of 'merely' reporting on current events, slow journalism makes sense of the world through the knowledge, interpretations, assessments, and appraisals of a particular journalist (Le Masurier, 2015). Cultivating the required insight is a slow process. In Musta laatikko productions, the speakers are encouraged to choose a topic which they have a longtime interest in and which sparks their personal enthusiasm (Lyytinen, 2020). In other words, the sense-making capacities of Musta laatikko journalists are built slowly along their professional career and involve a fair amount of tacit knowledge and even holistic wisdom that helps in projecting insight and interpretation (cf. Le Masurier, 2015).

What the live format adds to slow journalism is the embodied storytelling and the shared presence between a journalist and the audience. As with theatre plays, this liveness implies an immediacy that makes viewers feel that they are part of the story and invites them to engage in an active moral reflection and consideration of meanings and shared humanity (Barker, 2003). Liveness thus not only creates a shared reality between journalists and attendees but can establish a sense of a more immediate and direct connection to the issues and events journalists address - to reality 'out there.' In live performances, 'journalism literally becomes alive,' at least in the imagination of the attendees. In a survey for Musta laatikko attendees ( $N=510), 84 \%$ agreed that the performances made them feel connected to the performing journalist (Lyytinen, 2020). In open-ended responses, one respondent elaborated this as follows: "Black Box [Musta laatikko] created a more intimate and deeper connection to news and the people behind it" (Lyytinen, 2020, p. 49). While the live performance of news undoubtedly is a particularly powerful experience, similar kind of intimacy and co-construction of journalistic knowledge can take place in other journalistic communities, such as shared messaging groups between journalists and citizens (Kligler-Vilenchik \& Tenenboim, 2020). Thus, a potential way to replicate the power of live events in journalism broadly is by combining slow journalism with audience communities (Malmelin \& Villi,
2016). The following section introduces a third potential element: eudaimonia.

\section{Eudaimonic Media}

As news organisations seek to re-engage with their audiences, they increasingly employ different forms of infotainment (Pelzer \& Raemy, 2020). Journalistic infotainment often engages audience members through complex reflection and a re-employment of traditional news values rather than immediate pleasure (Pelzer \& Raemy, 2020). Also in entertainment research, the focus is shifting from entertainment as hedonic enjoyment to more contemplative, meaningful, and affectively complex experiences (Oliver et al., 2018). These types of media experiences can be conceptualised as 'eudaimonic' (Ryan et al., 2013). Eudaimonic media refer to 'serious' but entertaining contents that transmit values, morality, and shared meaning, and reflect both the virtuous as well as the tragic aspects of human life (Frischlich, 2020). Eudaimonic contents elicit affects and reflections that users identify as 'meaningful' (Oliver et al., 2018).

Live journalism events arguably offer a particularly benign environment for eudaimonic journalism. Eudaimonia is conjured by the artistic and performative aspects of a live show, a sense of community among attendees due to physical proximity and shared reactions, and a direct, embodied connection to a journalist who mediates and makes sense of the news and the social world (cf. Dale, Raney, Janicke, Sanders, \& Oliver, 2017). These characteristics of live journalism encourage audience members to 'venture beyond their private lives' and engage in 'an active reflection of shared meanings.' In other words, live journalism expresses two core dimensions of eudaimonic experiences: 'selftranscendence' and 'intrinsic motivation' (Oliver et al., 2018; Ryan et al., 2013).

Self-transcendent eudaimonic experiences involve 'truth-seeking,' an open-ended search for insight and meaning (Bartsch \& Schneider, 2014). Self-transcendent experiences can arise when viewers or readers recognize elements of shared humanity in media content, such as tragedies of the human condition or an interconnectedness with causes beyond oneself (Dale et al., 2017). Self-transcendent content can increase appreciation for the natural and the human world by encouraging audiences "to look beyond [their] own concerns, to recognize moral beauty, and to feel unity with humanity and nature" (Oliver et al., 2018, p. 380).

Intrinsic motivation, in turn, concerns the core psychological needs of autonomy, competence, and (social) relatedness (Ryan \& Deci, 2000). Satisfying intrinsic needs is considered eudaimonic as their fulfilment can foster self-expression, psychological well-being, and a sense of being one's true self (Ryan, Huta, \& Deci, 2008). One need not necessarily carry out self-determined acts because perceiving such acts in others can be enough to arouse similar sentiments in oneself (Oliver et al., 
2018). Through self-transcendence and the fulfilment of intrinsic needs, eudaimonic experiences can make a person feel aesthetically, affectively, and morally elevated. Eudaimonic media are thus often referred to also as 'inspirational media' (Dale et al., 2017).

In the context of journalism, the study of eudaimonic media experiences is only emerging (Oliver et al., 2018). Results from previous research echo the social and information-processing dimensions of live journalism. Hard news paired with contemplative and moving eudaimonic elements can encourage individuals to reflect on political issues, heighten their interest in news topics, and motivate further information seeking (Bartsch \& Schneider, 2014). Eudaimonically entertaining political communication, such as political talk shows, can enhance and deepen the audience's understanding of issues (Vorderer \& Reinecke, 2015). Newsgames can encourage the passing on of information about the issues addressed (Lin \& Wu, 2020), and users are more likely to share inspirational news stories within their social networks (Ji et al., 2019).

A strengthened interest toward the world and ethical reflection on it are typical of eudaimonic journalism. Grizzard et al. (2017) find that displays of graphic violence in broadcast news increases moral sensitivity and eudaimonic motivations such as willingness to help. News content about helping the homeless and fundraising for medical treatment can elicit morally elevated affects in readers and enhance a universalist sentiment of being connected to other people (Waddell \& Bailey, 2017). Pjesivac, Ahn, Briscoe, and Kim (2020) observe that a sense of spatial presence in $360^{\circ}$ video war news stories can lead to eudaimonic enjoyment evoked by promoting an understanding of the larger world of foreign affairs, reconsideration one's life values against that context, and an enhanced sense of agency and selfdeterminacy in the news experience. This in turn can increase intent to seek further information (Pjesivac et al., 2020).

The above examples show how eudaimonic news contents often focus on life's tragedies. Part of what makes eudaimonic narratives meaningful is that they support viewers and readers in contemplating that which is normally avoided. Eudaimonic enjoyment is induced by confronting and processing painful truths about the self, outside reality, and the fragility and preciousness of human life (Bartsch \& Schneider, 2014; Slater, Oliver, \& Appel, 2019). This can be seen as an opportunity for the employment of eudaimonia in journalism that equally often describes difficult events and complex issues with no easy answers.

In all, eudaimonia in journalism can foster affective and ethical contemplation of news, something which can enhance sense-making and help reflect on 'higher' meanings in news events. Eudaimonia can lead to prosocial behaviour, such as passing on information about news events and it encourages a re-focus from one's own life towards the surrounding world. What live jour- nalism can add are the shared and communal experiences around news, as described in the previous section. Tenenboim and Stroud (2020) draw on the concept of autopoietic feedback from the literature on theatre to understand the impact of live journalism on the audience. An autopoietic feedback loop refers to the interaction between actors and spectators through which a theatre performance, or a live journalism story, comes into being (Tenenboim \& Stroud, 2020). The gestures and expressions of a journalist and the attendees' reactions to them create a shared reality in which the stories become alive. This is expressed by both audience members and journalists when they compare live journalism events to a "campsite community" or "campfire stories" (Adams, 2020; p. 11; Lilja, 2020, p. 53).

Autopoietic feedback loops need not be restricted to live journalism. They are an example of broader reciprocal journalism which emphasises the direct (one-toone), indirect (one-to-many; community benefit), and sustained (long-lasting) exchanges between journalists and audience members (Lewis, Holton, \& Coddington, 2014). Practices of reciprocity are the basis of community formation: Communities are born of exchanges of mutual benefit (Tenenboim \& Stroud, 2020). If journalists are to forge a communal bond with audiences beyond engagement metrics, they may have to indulge in mutual and often personal exchanges. Loosen et al. (2020) label the latest phase of audience-journalism relationships a 'reciprocity phase' which underlines a need for sensitivity and responsiveness to audience needs and reactions. Reciprocity is also an inherent part of Musta laatikko, whose producers conceive their stories as gifts to audiences: They offer the audience something unique and exclusive, be it novel insight or 'souvenirs' from reporting trips (Lyytinen, 2020). Reciprocity and mutual feedback loops can support eudaimonic experiences as they potentially increase a sense of autonomy and competence in audience members, and through selftranscendence, they are drawn more deeply into journalistic stories (cf. Tenenboim \& Stroud, 2020). This can induce a state of 'liminality': a psychological and affective state of in-betweenness where distinctions between dichotomies, such as reality and performance, become blurred (Tenenboim \& Stroud, 2020). A theatre setting can suppress the ego of the attendees (Adams, 2020), something which other practices of journalistic reciprocity and community-building might also produce.

\section{Data and Method}

The data consists of the 16 manuscripts of Musta laatikko spring and autumn 2019 productions. The manuscripts are journalistic stories written by the journalists of Helsingin Sanomat, and presented by them in their own voices, word-by-word, on the main stage of the Finnish National Theatre. Each manuscript is approximately 1,100 words in length and is presented live in approximately 15 minutes. The topics for each production of 
eight performances are selected to reflect the topic selection in a newspaper or a news magazine issue. The specific topics in the two 2019 productions ranged from a reportage from the war-ravaged Syria and a historic analysis of the pending Finnish health and social services reform to an uplifting piece about the relationship Finns have with their hair, as well as a feature story about the artificial intelligence assisted composing of music. Of the 16 manuscripts analysed, seven can be labelled under politics. Six are human interest stories addressing difficult social relationships and hardships in life or reflect the social reality in general. Three cover arts and culture.

The Musta laatikko production is a specimen of 'meaningful media' (Vorderer \& Reinecke, 2015). Through their stories, Musta laatikko journalists seek to convey their own fascination and the sense of the meaningfulness of a topic (Lyytinen, 2020). In an affectively immersive manner, they seek to create a "shared reality between a journalist and the audience," as one editor commented at Musta laatikko rehearsals. Because of the emphasis on shared meaning, eudaimonia was chosen as a concept to understand the live journalism of Musta laatikko.

The contents of the collected manuscripts were analysed by employing a conceptual typology of two eudaimonic dimensions: 'self-transcendence' and 'fulfilment of intrinsic needs' (Oliver et al., 2018; Ryan \& Deci, 2000). The analysis was initiated with an open coding of the manuscripts. Using the qualitative analysis software NVivo, excerpts of text were given short descriptive labels summarising what was being said (Strauss \& Corbin, 1990). For instance, an excerpt reading "it is 30 years to the year 2049" was labelled as 'time; future.' The labelled excerpts were then categorized according to thematical similarity. This resulted in four sub-categories of self-transcendence, as described in Section 5.1.

A similar process was conducted regarding the fulfilment of intrinsic needs (Ryan \& Deci, 2000). Categories of open coding were further categorised, if applicable, under the three core intrinsic needs: 'autonomy' (descriptions of individuals or other actors who make independent choices or reflect their activities and goals), 'competence' (descriptions of individuals or other actors who perform well in particular areas), and 'relatedness' (descriptions of social relationships and mutual care; Ryan et al., 2008). A thematic category of 'independent journalist' from open coding was, for instance, placed under the category of autonomy. Finally, excerpts placed under the three categories of intrinsic needs were compared with each other, resulting in two subcategories under each intrinsic need, as elaborated in Section 5.2 (Strauss \& Corbin, 1990). All in all, eudaimonic elements proved to prevail in the manuscripts: Excluding factual reporting, the manuscripts are almost entirely coded under the employed typology of eudaimonia.

\section{Results}

\subsection{Self-Transcendence}

\subsubsection{Time}

The manuscripts imply an extended temporal existence by presenting the present moment in continuum with the past and the future. In one manuscript, for instance, the journalist examines how Finland, a country whose industry was virtually built on forestry, was able to survive and prosper over the following 100 years to the point where now forestry is in peril in many industrial towns (Manuscript 1, hereafter M1). Eudaimonic contents can encourage a reflection on the tragic and the emotionally difficult (Bartsch \& Schneider, 2014). The above journalist can be seen as gently pushing their audience to acknowledge and reflect on the 'hard truths' facing such a fundamental industry for Finland and to contemplate its uncertain but possibly positive futures. This can potentially help audience members make sense of the contemporary moment and its potential trajectories. Here especially the Musta laatikko stories appear as slow journalism: They detach from the daily and weekly news cycles to longer temporalities which span decades or even centuries. Making sense of the news and reflecting on their different dimensions can require a detachment from the instantaneity of daily news, which skews towards particular events and consensual viewpoints (Craig, 2016). Longer temporalities allow for a synthesizing and interpretive sense-making that can explore the broader and deeper trends, ideas, values, and issues behind news reports and analyses (Le Masurier, 2015).

Presenting the future as open, uncertain, and precarious is typical of the manuscripts. Besides the economy, contingent societal futures cover climate change (M3), Russia (M5, M15), the ageing population (M9), urban planning (M13), and the European Union (M6). The manuscripts not only probe uncertain futures but offer solutions to cope with the uncertainty. Uncertainty is alleviated by creating 'hope' through technological solutions, representative democracy, positive visions, and references to tradition ( $M 1, M 3, M 5, M 6)$. Moreover, future-oriented reflections can entail a sense of 'purpose': present events draw meaning from imagined future events (Baumeister, Vohs, Aaker, \& Garbinsky, 2013). Hence, for instance, when a journalist reminded the audience how Finnish health and social services reform has to take the ageing population into account, the journalist potentially aroused a sense of national purpose in how the situation could be managed (M9).

Besides the future, the manuscripts employ extended time to make sense of the contemporary. A journalist claiming rap music as "the most important music of our times" (M12) invites the audience to think of the present as a comprehensive whole ("our times") and highlights rap music as a key to understanding it. References to history, similar to future projections, 
contextualise the contemporary as part of historical processes and show how the present reality is not inevitable but could be otherwise. When a journalist, for instance, laments how the rising popularity of spirituality is being hindered by the historical processes of the "scientific revolution" and modernisation, they simultaneously imply a future in which spirituality is more socially accepted (M14). On the other hand, history can appear as path-dependence and closed futures, such as when the Russian federation was suggested to be still undergoing a disintegration process following the fall of the Soviet empire (M15). All in all, Musta laatikko manuscripts strive to promote a sense of meaningfulness in the attendees: Studies show that thinking about the past and imagining the future are strongly associated with a meaningful life (Baumeister et al., 2013).

\subsubsection{Life and Death}

The theme of transcendent time is continued in excerpts that contemplate life and death. Such content can arouse gratitude and foster moral virtue, and thereby create eudaimonic experiences (Dale et al., 2017). Regarding death, war appears as the most tragic human condition (M2, M5, M15): "I was a reporter in the Bosnian War, and I never want to see anything like that again" (M6). On the contrary, peace, joy, and "good life" are described as the most precious things in human life (M2, M4, M6). Living a good life is presented as consisting of, for instance, meaningful relationships, hobbies, openness, and broad-minded attitudes (M2, M4, M5). The manuscripts thus encourage opening up to the world as a means to pursue a good and meaningful life. A person's "realization of complete human life" is presented as a social rather than individual pursuit (Ryan et al., 2013, p. 120). Previous studies also suggest that involvement with things beyond oneself promotes a sense of meaningfulness (Baumeister et al., 2013).

Contemplating life and death can help appreciate life as fleeting, finite, and precious (Oliver \& Hartmann, 2010). The manuscripts reflect life after the loss of a spouse, the communication with the dead in spiritualistic sessions, or the sudden loss of human life through accidents (M3, M11, M14, M15). Like hope offered to soften uncertainty towards the future, the singular finiteness of human life can be transcended by the cyclical nature of life and death: Death is not the end, but "a beginning for the new" (M11). The cycle of life and death concerns only individuals, but also industrial towns, generations, and entire populations ( $M 1, M 4, M 5, M 9)$. Here again, the manuscripts tilt away from the particular to reflect that which connects singular phenomena.

\subsubsection{Democracy and Public Life}

An individual's life can be transcended, and new meaning cultivated, through an imagined political community. When a journalist claims that rap music can "wake and activate young people politically," they allude to a higher ethical-political plane attainable through music (M12). Caring for issues beyond one's immediate interests, such as the European integration, connects individuals to universal, transcendental values such as the peace that the European Union allegedly upholds (M6). Similarly, political participation can create hope in our ability to reverse climate change and shift an individual's focus away from oneself, from "dwelling in bad conscience" to creating shared hope of an ecologically sustainable future (M3).

The manuscripts can articulate shared political problems, suggest new issues for the political agenda, and invite audience members to reflect on topics beyond their private concerns. For instance, one journalist argues that the issues of elderly people without children are not currently conceived of as political problems although they should be (M4). Often the suggested issues address marginalized or underrepresented groups. Representing under-served groups invites audience members to step out of their political 'comfort zone' and consider issues beyond their usual concerns. It is particularly "female rap musicians" who "bring forth new social problems" and introduce listeners to new socially conscious political ideas, such as feminist thought (M12). Another manuscript approaches criminal biker gangs as a sociopolitical issue of social exclusion and deprivation (M10).

Democracy and public life pertain to 'elevation' as a particular element of self-transcendence (Dale et al., 2017). Considering and acting upon issues that transcend one's self-interest are seen as manifestations of moral beauty and humanity's 'better nature' (Dale et al., 2017). In several manuscripts, a journalist explicitly elevates public participation, stating that it should not be treated with "apathy" (M6). When a journalist, for instance, ends their piece by accentuating how "all of us are a politician's boss," they invoke a democratic ideal of the demos as the ruling body of free citizens (M3).

\subsubsection{Nature}

Descriptions of nature can foster self-transcendence through 'awe' and 'elevation' in the face of the beauty and vastness of nature (Dale et al., 2017). The manuscripts describe natural phenomena, such as climate change, as a superior force which human societies cannot control (M3). Evocative scenes such as one describing a Finnish wintertime tradition of ice swimming where "small humans" take a dip in a hole carved in the ice suggest nature as a both benevolent and preeminent force (M16). The smallness of humans is implied also in another manuscript where the journalist marvels at how we probably still are unaware of all the existing natural laws and phenomena (M14). The manuscript nods toward a transhumanist expansion: if exposed and harnessed, these unknown forces could vastly expand human capacities (M14). 
Despite being appreciated, nature is mostly described as lacking an inherent value. Moreover, nature is drawn distinct from the human world. An implied ideal state is a balance between humans and nature, an expression of moral beauty despite the pragmatic approach (Dale et al., 2017). The balance can manifest for instance as carbon neutrality or removing microplastics from natural environments (M1, M3). If nature is described as valuable in itself, the value is foremost aesthetic, appreciating the beauty of community gardens, diamond mines, walrus packs, or untouched forests (M1, M3, M4, M5).

\subsection{The Fulfilment of Intrinsic Needs}

\subsubsection{Autonomy}

\subsubsection{Critical, Independent Journalist}

The manuscripts present the journalists as autonomous when they question authorities and prevailing assumptions. One journalist is sceptical as to whether the rosy futures propagated by the Finnish forest industry are "baseless hype" (M1), and another claims children are not as central to wellbeing as is often assumed (M4). Such critical independence can make journalists appear as exemplary of autonomous, self-determinant individuals. An aura of uncompromising independence is strengthened by criticisms towards the journalistic profession. A foreign reporter, for instance, laments how fixated journalists are on havoc and suffering: such bleak depictions illuminate only one aspect of the messy reality of war but "give kicks" to reporters (M2). Another journalist points to the narrowness of news criteria and gives "weird" and "unexplained" phenomena as an example of a topic journalists often dismiss (M14).

The journalists appear as autonomous also when they offer critical assessments of issues. In such passages, a journalist appraises what they think are among the most important aspects in a particular case: "What is the meaning of all of this?" (M15). The explanations range from the core problems in the Finnish health and social services reform to why some people want to become a member of criminal biker gangs (M9, M10). One journalist even cries out how an unrealised urban transportation plan "does not make any sense!" and simultaneously implicitly criticises Helsinki's urban planning (M13). Such appraisals show journalists as highly autonomous, virtuous characters who are able to make sense of the messy reality on behalf of the audience. The appraisals, such as the previously mentioned examples of a critical mindset, emphasized confronting truths that are not always pleasant-an appropriate eudaimonic role for journalists particularly (Bartsch \& Schneider, 2014). In the spirit of reciprocal journalism, such reflections can be seen as sense-making "gifts" journalists give their audiences (Lewis et al., 2014).

\subsubsection{Independent Individual}

Several manuscripts describe independent individuals who think for themselves, make autonomous decisions, and have an evolved self-understanding. An independent reflection and assessment of life choices and aims is a critical prerequisite for autonomous and eudaimonic living (Ryan et al., 2013). Individuals with a capacity for volition and mindful reflection are thus implicitly portrayed as role models audience members can follow in their strive towards an independent life of self-determination. One manuscript, to give an example, depicts a woman, who in the 1960s, "had other plans" than what was expected of women at that time (M4). By the portrayal, the manuscript invites viewers to think for themselves instead of following social conventions that restrict individuals' choices. Autonomy and independence are, however, not presented as a sole responsibility of individuals but as socially produced. Another journalist asserts how schools should teach children "to think for themselves and apply what they have learned" (M5). The merging of individual and social autonomy is exemplified also by active citizenship and taking part in representational politics (M3). This is in line with research showing that a sense of autonomy and relations with other people are strongly interrelated (Reinecke, Vorderer, \& Knop, 2014).

\subsubsection{Competence}

\subsubsection{Competent Journalist}

The manuscripts present the journalists as competent by highlighting their expertise, the risks and effort they take during reporting, and how well-versed they are in particular topics. Many bring up the amount of background reporting they have undertaken. Extensive research, often years-long, can result in a book instead of 'mere' news articles (M4, M10, M14). Acquiring expertise is not only hard work but also involves a personal involvement and nerdy interest, a passion towards one's work: "I am quite passionate about the European Union, and during the recent years I have become somewhat of an EU nerd" (M6). Passionate interest and a 'nerdy' focus are prime examples of competence attained through intrinsic motivation (Mills, Milyavskaya, Mettler, Heath, \& Derevensky, 2018; Ryan \& Deci, 2000). They also express the ideal of slow journalism for deep, personally engaged reflection of news events (Le Masurier, 2015).

\subsubsection{Competent Individuals}

Besides journalists, the manuscripts can describe other professionals or ordinary people as competent. Competent professionals range from Finnish world-class hairdressers to a pioneer in computer-assisted music composition. Although competence can be framed as an individual trait, such as exceptional creativity, it is presented as attainable by virtually everyone through 
learning and growing as a person. Despite being a psychological feature, capacities for learning are socially produced (Ryan \& Deci, 2000). This is illustrated in a manuscript that brings up how rap music has inspired youngsters with learning difficulties to "analyse texts like literature majors" (M12). The narrative of mastery and constant growth through learning can be broadened to an entire nation, its history, and the future: "We Finns have forests, water, and intelligence. Now we have to once again learn to make something new out of them" (M1).

\subsubsection{Relatedness}

\subsubsection{Social Relationships}

References to social relationships can include the warm and communal feelings held towards others in a Siberian village (M5). Appropriate for journalistic stories, social relationships are not presented as a private but foremost as a public and political matter. This is of interest as applications of self-determination theory to politics are virtually absent (Russo \& Stattin, 2017). A lack of healthy social relationships is given as one possible explanation for why some join criminal organisations (M10). One journalist suggests a new social arrangement for ageing societies: communal living and friendship of the elderly (M4). Another argues how in the eyes of officials and bureaucrats the nuclear family and marriage still often are the norm, suggesting other social arrangements should be treated equally (M11).

\subsubsection{Relationships with and between Audience} Members

The journalists seek to create a connection with the audience members by addressing them directly by using the pronouns "you," "us," and "we," often in a lighthearted chit chat mode. The connection can reach beyond the event to include both the journalist and the audience in a shared social or political whole. This can elevate what is being said to have a higher purpose such as peace and democratic participation: "If we want to live in Europe where peace prevails, we have to care about the European Union and show it" (M6). Experiencing life as meaningful entails being part of a shared culture and collective affects (Baumeister et al., 2013). A sense of shared social, cultural, and political reality can thus enhance eudaimonic meaningfulness in audience members. A shared reality and social bond are often implied by referring to "us Finns" (M1, M6, M7). This includes invitations to serious national self-reflection, such as reminding how Finland has its own blind spots regarding social equality and human rights (M9, M10, M12).

The inclusion of the journalist and the audience in a shared social entity can be seen as a means to make the topic at hand more affectively 'real.' This is reflected by Adams (2020, p. 2) who argues that live journalism could bring "a community together to explore the truth of shared experiences." A truth of shared experiences is implied by a journalist who states that "more than half in this theatre hall have experienced something they cannot explain" (M14). A shared truthiness can also be affectively underlined by a journalist's urge to tell a particular story to the audience ("I wanted to tell you," M3). A sense of the meaningfulness of a topic is thus created not only by a journalist's personal enthusiasm but also by the potential socially shared interest and the topic's place in a shared social reality.

\section{Conclusion and Discussion}

This article has investigated an emerging journalistic form of live journalism in which journalists present their stories to a live audience. Analysing manuscripts of Musta laatikko, a Finnish live journalism production, the article asks whether and how eudaimonia is employed in the manuscripts (RQ1) and how the ideas of 'eudaimonic live journalism' could be applied in other forms of journalism (RQ2). Eudaimonia refers to non-hedonic, 'serious' but entertaining journalism which reflects on life's meaning and pursues personal and social growth (Vorderer \& Reinecke, 2015). The manuscripts were analysed along two dimensions of eudaimonic media experiences: self-transcendence and the fulfilment of the intrinsic needs for autonomy, competence, and relatedness (Dale et al., 2017; Oliver et al., 2018). Regarding 'self-transcendence,' stories can support audiences to comprehend the news by contextualising them as part of history and anticipated futures. Eudaimonic journalism can thus transcend the present as the temporal locus of journalism (Carlson, 2020). The stories can also transcend everyday existence by being a reminder of how finite and precious human life is. Similarly, democratic and public participation can be portrayed as a meaningful moral and universalist pursuit, rather than a citizen responsibility to be fulfilled (Pjesivac et al., 2020). The manuscripts also approach nature from an ethical perspective and appreciate its awe-inspiring immensity (Oliver et al., 2018).

Interactive news forms, such as $360^{\circ}$ video or newsgames, have been shown to induce eudaimonic experiences by allowing users to feel that they can determine their own futures and transcend boundaries (Pjesivac et al., 2020). Lacking in interactivity, written and performed news contents can provide a sense of fulfilling one's intrinsic needs through an identification with virtuous individuals (Cohen, 2001; Wirth, Hofer, \& Schramm, 2012). In Musta laatikko stories, 'autonomy' engages both journalists and ordinary people alike in critical and independent thinking. 'Competence' can include portrayals of high expertise, evolved skills, creativity, and a passion towards one's interests. Rather than depicting competence as a personal trait, news stories can highlight ways to collectively support individuals' competence (Ryan \& Deci, 2000). Regarding social 'relatedness,' 
the manuscripts describe different types of communal relationships. Imagining warm and benign relationships can be intrinsically fulfilling as such. Moreover, journalists can envelop themselves and their audience within a shared 'us' and thereby invite them to reflect on shared meanings, collective truths, and the social and ecological challenges faced by society (Adams, 2020; Bartsch \& Schneider, 2014).

Eudaimonia broadens the roles and functions of news. Eudaimonic news transcends observable facts and processes to reflect on the purpose and meaning of individual and collective lives. Eudaimonic journalism can take part in retaining and renewing collective values and help make better sense of the time we are living in, including the futures we are potentially heading toward (Adams, 2020; Oliver \& Raney, 2011; Rieger \& Klimmt, 2019; Vodanovic, 2020). However, eudaimonic media is not only a positive phenomenon. For instance, Frischlich (2020) shows how eudaimonically inspiring contents can be exploited to bolster support for terrorist networks. The deep audience engagement eudaimonia promises can be applied also for less severe manipulative purposes. Business organisations, NGOs, communications consultancies, and other actors at the 'peripheries' of journalism could employ eudaimonia within their inhouse news content to promote their interests.

Live journalism can be seen as a particularly eudaimonic form of journalism because it, first, invites participants to suppress their ego (Adams, 2020) and become part of a temporary community and shared social reality created in the live event. Like theatre, live journalism performances can entice a liminal transcendent experience where the boundaries become blurred, both between reality and performance and between the performer and spectators (Tenenboim \& Stroud, 2020). Second, live performances highlight the agency and autonomy of participants as active sense-makers of news stories and, through their responses to the performing journalist such as laughter or body language, become co-creators of the event. Live journalism stories come into being in such 'autopoietic feedback loops' between a journalist and audience (Tenenboim \& Stroud, 2020).

Although live journalism may provide an ideal form to incorporate eudaimonic sentiments in journalistic stories, its devices and practices can be applied to journalism broadly. This article suggests two ways. The first is to build reciprocal relationships between journalists and news users. As a practice for building mutual relationships, journalists can, for instance, offer communityoriented materials, such as photos or commentaries, that are of interest to community members (Tenenboim \& Stroud, 2020). A direct and intimate relationship between journalists and audience members can be forged by using new means of news distribution and community building such as newsletters, WhatsApp, Signal, or other messaging groups (e.g., Kligler-Vilenchik $\&$ Tenenboim, 2020). Through such groups, audience members can both transcend their private life, into pub- lic and communal life, and enhance their sense of agency and autonomy towards the news.

The second way to incorporate eudaimonic sensibility in journalism is through its content. The eudaimonic content and perspectives observed in Musta laatikko manuscripts could be published in a newspaper or news magazine, for instance. The article suggests slow journalism as a particularly apt form for non-live eudaimonic journalism. The slow journalism dimensions of reflection, sense-making, literary styles, and extended temporality all pertain to eudaimonia (see Le Masurier, 2015). Like slow journalism, eudaimonic journalism offers audience members new means to deal with and process the increasingly complex social reality (Craig, 2016).

Regarding professional journalism, while the collective sense-maker and truth-seeker role are not necessarily problematic as such, the role includes unexplored implications. Which values and purposes would journalists choose to promote, and which to ignore? How would outside elements such as audience metrics and business models influence the ways 'meaningfulness' is represented? Professional journalists as explorers of collective purpose and meaning also connect to the breadth of their target audiences. As eudaimonia addresses shared identities and a personal sense of meaningfulness, niche audiences with shared tastes may prove the most fitting for eudaimonic journalism (Ji et al., 2019). Applied widely, eudaimonia could thus deepen the ongoing fragmentation of news audiences and exacerbate inequalities in news consumption between socio-economic groups (Pelzer \& Raemy, 2020). Journalistic content that expresses eudaimonic sentiments, especially autonomy and competence, would probably attract particularly middleclass audiences already proficient in self-reflection and self-improvement (Kreiss, 2018).

\section{Acknowledgments}

This research was funded by the Helsingin Sanomat Foundation (no. 201800133).

\section{Conflict of Interests}

The authors declare no conflict of interests.

\section{References}

Adams, C. (2020). News on stage: Towards reconfiguring journalism through theatre to a public sphere. Journalism Practice. Advance online publication. https:// doi.org/10.1080/17512786.2020.1771754

Andersen, K. (2020). Realizing good intentions? A field experiment of slow news consumption and news fatigue. Journalism Practice. Advance online publication. https://doi.org/10.1080/17512786.2020. 1818609

Barker, M. (2003). Crash, theatre audiences, and the 
idea of 'liveness.' Studies in Theatre and Performance, 23(1), 21-39.

Bartsch, A., \& Schneider, F. M. (2014). Entertainment and politics revisited: How nonescapist forms of entertainment can stimulate political interest and information seeking. Journal of Communication, 64(3), 369-396.

Baumeister, R. F., Vohs, K. D., Aaker, J. L., \& Garbinsky, E. N. (2013). Some key differences between a happy life and a meaningful life. The Journal of Positive Psychology, 8(6), 505-516.

Carlson, E. (2020). Speculative journalism can help us prepare for what's to come: Could it also promote misinformation? Nieman Reports. Retrieved from https:// niemanreports.org/articles/speculative-journalism

Cohen, J. (2001). Defining identification: A theoretical look at the identification of audiences with media characters. Mass Communication and Society, 4(3), 245-264.

Craig, G. (2016). Reclaiming slowness in journalism. Journalism Practice, 10(4), 461-475.

Dale, K. R., Raney, A. A., Janicke, S. H., Sanders, M. S., \& Oliver, M. B. (2017). YouTube for good: A content analysis and examination of elicitors of self-transcendent media. Journal of Communication, 67(6), 897-919.

Frischlich, L. (2020). \#Dark inspiration: Eudaimonic entertainment in extremist Instagram posts. New Media \& Society, 23(3), 554-577. https://doi.org/10.1177/ 1461444819899625

Grizzard, M., Huang, J., Weiss, J. K., Novotny, E. R., Fitzgerald, K. S., Ahn, C., ... Chu, H. (2017). Graphic violence as moral motivator: The effects of graphically violent content in news. Mass Communication and Society, 20(6), 763-783.

Ji, Q., Raney, A. A., Janicke-Bowles, S. H., Dale, K. R., Oliver, M. B., Reed, A., ... Raney, A. A. (2019). Spreading the good news: Analyzing socially shared inspirational news content. Journalism \& Mass Communication Quarterly, 96(3), 872-893.

Kligler-Vilenchik, N., \& Tenenboim, O. (2020). Sustained journalist-audience reciprocity in a meso newsspace: The case of a journalistic WhatsApp group. New Media \& Society, 22(2), 264-282.

Kormelink, T. G., \& Costera Meijer, I. (2015). Truthful or engaging? Digital Journalism, 3(2), 158-174.

Kreiss, D. (2018). The networked self in the age of identity fundamentalism. In Z. Papacharissi (Ed.), A networked self: Platforms, stories, connections (pp. 12-28). New York, NY: Routledge.

Larson, C. (2015). Live publishing: The onstage redeployment of journalistic authority. Media, Culture \& Society, 37(3), 440-459.

Le Masurier, M. (2015). What is slow journalism? Journalism Practice, 9(2), 138-152.

Lewis, S. C., Holton, A. E., \& Coddington, M. (2014). Reciprocal journalism. Journalism Practice, 8(2), 229-241.

Lilja, E. (2020). Toimittajat parrasvaloissa: Helsingin
Sanomien Musta laatikko-esiintyjien kokemuksia livejournalismista [Journalists in the spotlight: Experiences of the Helsingin Sanomat Black Box performers on live journalism] (Unpublished Master's thesis). University of Jyväskylä, Jyväskylä, Finland.

Lin, J.-H. T., \& Wu, D.-Y. (2020). Newsgames for the greater good: The effects of graphic realism and geographic proximity on knowledge acquisition and willingness to help. Journalism \& Mass Communication Quarterly, 97(1), 30-51.

Loosen, W., Ahva, L., Reimer, J., Solbach, P., Deuze, M., \& Matzat, L. (2020). 'X Journalism': Exploring journalism's diverse meanings through the names we give it. Journalism. Advance online publication. https:// doi.org/10.1177/1464884920950090

Lyytinen, J. (2020). Pulling back the curtain: How live journalism is re-engaging news audiences (Journalist Fellowship Paper). Oxford: Reuters Institute. Retrieved from https://reutersinstitute.politics.ox. ac.uk/sites/default/files/2020-08/RISJ_Final\%20 Report_Jaakko\%20Lyytinen_2020_FINAL\%20\% 281\%29.pdf

Malmelin, N., \& Villi, M. (2016). Audience community as a strategic resource in media work. Journalism Practice, 10(5), 589-607.

Mills, D. J., Milyavskaya, M., Mettler, J., Heath, N. L., \& Derevensky, J. L. (2018). How do passion for video games and needs frustration explain time spent gaming? British Journal of Social Psychology, 57(2), 461-481.

Oliver, M. B., \& Hartmann, T. (2010). Exploring the role of meaningful experiences in users' appreciation of "good movies." Projections: The Journal of Movies and Mind, 4(2), 128-150.

Oliver, M. B., \& Raney, A. A. (2011). Entertainment as pleasurable and meaningful: Identifying hedonic and eudaimonic motivations for entertainment consumption. Journal of Communication, 61(5), 984-1004.

Oliver, M. B., Raney, A. A., Slater, M. D., Appel, M., Hartmann, T., Bartsch, A., . . . Das, E. (2018). Selftranscendent media experiences: Taking meaningful media to a higher level. Journal of Communication, 68(2), 380-389.

Pelzer, E., \& Raemy, P. (2020). What shapes the cultivation effects from infotaining content? Toward a theoretical foundation for journalism studies. Journalism. Advance online publication. https://doi.org/ 10.1177/1464884920922704

Pjesivac, I., Ahn, S. J., Briscoe, A., \& Kim, S. (2020). $360^{\circ}$ journalism and information seeking: The role of enjoyment and spatial presence. Paper presented at the 70th International Communication Association Annual Conference.

Reinecke, L., Vorderer, P., \& Knop, K. (2014). Entertainment 2.0? The role of intrinsic and extrinsic need satisfaction for the enjoyment of Facebook use. Journal of Communication, 64(3), 417-438.

Rieger, D., \& Klimmt, C. (2019). The daily dose of 
digital inspiration 2: Themes and affective user responses to meaningful memes in social media. New Media \& Society, 21(10), 2201-2221. https://doi.org/ $10.1177 / 1461444819842875$

Russo, S., \& Stattin, H. (2017). Self-determination theory and the role of political interest in adolescents' sociopolitical development. Journal of Applied Developmental Psychology, 50, 71-78.

Ryan, R. M., \& Deci, E. L. (2000). Self-determination theory and the facilitation of intrinsic motivation, social development, and well-being. American Psychologist, 55(1), 68-78.

Ryan, R. M., Huta, V., \& Deci, E. L. (2008). Living well: A self-determination theory perspective on eudaimonia. Journal of Happiness Studies, 9(1), 139-170.

Ryan, R. M., Huta, V., \& Deci, E. L. (2013). Living well: A self-determination theory perspective on eudaimonia. In A. Delle Fave (Ed.), The exploration of happiness (pp. 117-139). Dordrecht: Springer.

Slater, M. D., Oliver, M. B., \& Appel, M. (2019). Poignancy and mediated wisdom of experience: Narrative impacts on willingness to accept delayed rewards. Communication Research, 46(3), 333-354.
Strauss, A., \& Corbin, J. (1990). Basics of qualitative research: Grounded theory procedures and techniques (1st ed.). Newbury Park, CA, London, and New Delhi: Sage.

Tenenboim, O., \& Stroud, N. J. (2020). Enacted journalism takes the stage: How audiences respond to reporting-based theater. Journalism Studies, 21(6), 713-730.

Vodanovic, L. (2020). Aesthetic experience, news content, and critique in live journalism events. Journalism Practice. Advance online publication. https://doi. org/10.1080/17512786.2020.1796763

Vorderer, P., \& Reinecke, L. (2015). From mood to meaning: The changing model of the user in entertainment research. Communication Theory, 25(4), 447-453.

Waddell, T. W., \& Bailey, A. (2017). Inspired by the crowd: The effect of online comments on elevation and universal orientation. Communication Monographs, 84(4), 534-550.

Wirth, W., Hofer, M., \& Schramm, H. (2012). Beyond pleasure: Exploring the eudaimonic entertainment experience. Human Communication Research, 38(4), 406-428.

\section{About the Authors}
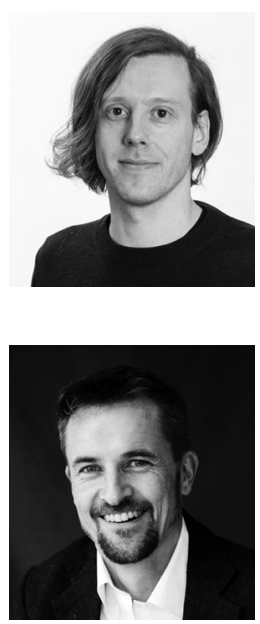

Juho Ruotsalainen (M. Soc. Sc.) is a PhD Candidate at the Finland Futures Research Centre, University of Turku. His doctoral thesis investigates the different ways pioneer journalists conceive of the futures of journalism. These conceptions produce future knowledge that influences how the journalism industry at large makes sense of its futures and develops new practices. Hence, rather than anticipating possible futures, the work critically analyses present knowledge that frames what is understood as plausible and preferable in the development of journalism.

Mikko Villi $(\mathrm{PhD})$ is Professor of Journalism at the University of Jyväskylä, Department of Language and Communication Studies. An emphasis in his work is on the contemporary context for journalism, especially new media platforms and social media. His key interest is the study of media organizations and media management. 